Please cite this article as:

Heyvaert, M., Maes, B., \& Onghena, P. (2010). A meta-analysis of intervention effects on challenging behaviour among persons with intellectual disabilities. Journal of Intellectual Disability Research, 54, 634-649. doi:10.1111/j.1365-2788.2010.01291.x 


\title{
A meta-analysis of intervention effects on challenging behaviour among persons with intellectual disabilities
}

Keywords: meta-analysis, intellectual disability, mental retardation, challenging behaviour

\author{
Abstract
}

Background: Persons with intellectual disabilities (ID) often show challenging behaviour. We review distinct interventions that are applied to treat these challenging behaviours, and analyse intervention effects and moderating variables.

Method: A literature search was conducted using the databases ERIC, PsycINFO, Web of Science and Medline. A random-effects meta-analysis was carried out, supplemented with sensitivity, subgroup, meta-regression, and publication bias analyses.

Results: Eighty potential articles were identified, from which 30 contained sufficient data to enable statistical meta-analysis. From these 30 studies, 18 described a biological, 13 a psychotherapeutic and 9 a contextual intervention, either applied alone or combined. The overall standardised mean difference was 0.671 ( $\mathrm{SD}=0.051)$. As shown by sensitivity analysis, this summary effect size is robust. Assessed through subgroup and meta-regression analysis, all tested moderators showed no statistically significant association with the treatment effects. After applying a funnel plot-, a fail-safe $\mathrm{N}-$, and Duval's and Tweedie's trim and fill-analysis, we conclude that our meta-analysis does not suffer much from publication bias effects.

Conclusions: Several biological, psychotherapeutic and contextual interventions effectively reduce challenging behaviours among persons with intellectual disabilities.

\section{Introduction}

Over the last decades, literature on the prevalence, impact, and treatment of challenging behaviour presented by individuals with intellectual disabilities (ID) has accumulated (Antonacci et al. 2008, Didden et al. 2006, Harvey et al. 2009, Kahng et al. 2002, McClintock et al. 2003, Moss et al. 1997, Prout \& Nowak-Drabik 2003). Examples of challenging behaviour include verbal and physical aggression, property damage and destructiveness, disruptive and antisocial behaviour, overactivity, temper tantrums, screaming, stereotyped and repetitive behaviour, general delinquency, and selfinjurious behaviour, like head punching, self-biting, skin picking, and hitting against hard objects or other body-parts (Allen \& Davies 2007, Benson \& Brooks 2008, Deb et al. 2001, Didden et al. 2007, Grey \& Hastings 2005).

Challenging behaviours are especially prevalent in individuals with ID, and the more severe the disability, the higher the likelihood of the presence of these behaviours (Borthwick-Duffy 1994, 
Cormack et al. 2000, Janssen et al. 2002, McIntyre et al. 2002). Most studies report prevalence rates of challenging behaviour among persons with ID between 10 and 20\% (Emerson et al. 2001, Kahng et al. 2002, Lowe et al. 1998), while some authors reporting substantially higher rates (Allen 2000, Cooper et al. 2009a, Crocker et al. 2006, 2007, Deb et al. 2001, Dekker et al. 2002, Gavidia-Payne \& Hudson 2002, Moss et al. 1997). The development of challenging behaviour is influenced by person- and environment-oriented factors, which often interact with each other. Examples of these factors that are frequently mentioned, are not only the age, gender and level of ID of persons, but also poor adaptive and social skills, psychological stress, inadequate problem-solving skills, impaired language, socioeconomic deprivation, negative life events, secondary disabilities and psychiatric disorders (Allen \& Davies 2007, Aunos et al. 2008, Blacher \& McIntyre 2006, Bradley et al. 2004, Chadwick et al. 2008, Collacott et al. 1998, Cooper et al. 2007, Crocker et al. 2007, de Ruiter et al. 2008, Dekker et al. 2002, Didden et al. 2007, Embregts et al. 2009, Hastings \& Mount 2001, Hemmings et al. 2006, Holden \& Gitlesen 2009, Janssen et al. 2002, Matson \& Rivet 2008, McClintock et al. 2003).

Challenging behaviours have a negative impact on persons with ID and their environment, inter alia because they increase risks on a reduced quality of life, stressful events, obstacles to social integration, and the need for costly residential care (Benson \& Brooks 2008, Blacher \& McIntyre 2006, Cooper et al. 2009a, Didden et al. 2006, Harvey et al. 2009, Hassiotis et al. 2008, Knapp et al. 2005, Matson \& Boisjoli 2009, McIntyre et al. 2002). Moreover, due to their recurrent character, challenging behaviours tend to become a lifelong challenge for the individuals with ID, their family, and the involved services (Cooper et al. 2009a, 2009b, Danquah et al. 2009, Murphy et al. 2005, Tenneij \& Koot 2008, Totsika \& Hastings 2009).

Because of the high prevalence and negative impact of challenging behaviours among persons with ID, considerably much research has been conducted on interventions in this area (Antonacci et al. 2008, Beail 2003, Deb et al. 2007, Grey \& Hastings 2005, Kahng et al. 2002, McGillivray \& McCabe 2006, Moss et al. 1997, Prout \& Nowak-Drabik 2003, Sohanpal et al. 2007, Sturmey 2004, Taylor 2002, 2005, Willner 2005). Treatment strategies that are frequently employed are biological and psychotherapeutic interventions, sometimes supplemented with contextual strategies (Ager \& O'May 2001, Benson \& Brooks 2008, Bouras 1999, Dösen \& Day 2001, Gavidia-Payne \& Hudson 2002, Grey \& Hastings 2005, Kahng et al. 2002, Mildon et al. 2008, Taylor 2002). Recently, some reviews and meta-analytic articles have studied these interventions for challenging behaviour among persons with ID (Brylewski \& Duggan 1999, Didden et al. 2006, Lotan \& Gold 2009, Matson \& Neal 2009, Prout \& Nowak-Drabik 2003, Shogren et al. 2004, Thomson et al. 2009a, 2009b). None of these articles included both the biological and the psychotherapeutic and contextual interventions, although it is interesting to compare effects of these three intervention types, either applied alone or combined, with each other. Further advantages of this meta-analysis that are often missing in previous reviews and meta-analytic articles, are the quality assessment of all included articles, the extensive moderator testing, and additional sensitivity and publication bias analyses. 
The main purpose of the present study was to review distinct biological, psychotherapeutic, and contextual interventions that are applied to treat challenging behaviour among persons with ID, and to analyse intervention effects and moderating variables. We did this by performing a meta-analysis, in order to boost the total sample size and effect precision by combining 'sufficiently' homogeneous results across studies. This was done by first describing the selected articles and the interventions they report. Second, we performed a meta-analysis in order to broadly explore intervention effects and possible moderating effects of study and participant variables. Additionally, we report on the quality assessment we carried out for each study included, and examine the moderating role of study quality for reported intervention effectiveness. The meta-analysis, supplemented with sensitivity, subgroup, meta-regression, and publication bias analyses that were carried out, is described in this article.

\section{Methods}

\section{Literature search and selection of studies}

The literature search was carried out using four electronic databases: ERIC, PsycINFO, Web of Science and Medline. We searched for articles reporting on biological, psychotherapeutic, or contextual interventions for challenging behaviour among persons with ID by combining key terms describing the target group and outcome variables. Applied key terms referring to the target group were intellectual disability, mental retardation, learning difficulty and complex/high support needs. Used key terms describing outcome variables were challenging behaviour, problem behaviour, behavioural problems, aggression, self-injury and self-injurious behaviour. We searched for these terms in singular and plural, in US- and UK-terminology. We only included English-language articles that described empirical studies and that were published in peer-reviewed journals between January 2000 and November 2008. The main focus of the included articles had to be the implementation of an intervention targeting challenging behaviour among persons with ID. We excluded articles that only reported on diagnostic instruments or only presented review material. Because we wanted to perform a meta-analysis, the selected articles had to contain data or sufficient statistical information to make a quantitative analysis feasible.

\section{Characteristics recorded for each study}

Some features were recorded for all studies included in the meta-analysis: intervention characteristics, intervention effects, methodological features, study characteristics, and participant features. We selected these features because of their relevance to the domain, as described in prominent literature (Altman et al. 2001, Jadad et al. 1996, Khan et al. 2001, Oxman \& Guyatt 1988, Shadish et al. 2002, van Tulder et al. 2003, Verhagen et al. 1998). First, we recorded for each study which treatment was implemented, thereby making a distinction between biological, psychotherapeutic, and contextual interventions, and possible combinations of two or three of these intervention types applied together in 
a single study (multimodal interventions). Second, intervention effects were determined for each study. Examples of challenging behaviour that are often the target in intervention studies are selfinjurious and stereotypic behaviour, and aggressive and destructive behaviour (Allen \& Davies 2007, Campbell 2003, Didden et al. 2006, Grey \& Hastings 2005, Totsika \& Hastings 2009). Third, some methodological features were recorded. We looked at each study design and recorded whether the authors implemented an experiment, a quasi-experiment, a natural experiment, or a non-experimental design. Furthermore, we described the data collection procedure: did the authors use tests or physiological measures, questionnaires, observations, interviews, and/or other data collection methods? In addition, we looked whether indices of reliability of applied data collection instruments were reported. Fourth, we described two study characteristics: the length of the research period (the average time between the first and last measurement for each studied group of participants) and the continent where the research took place. Fifth, four participant features were recorded for each article: the number of participants, and their gender, age, and level of ID. In addition, we graded the quality of all articles included in the meta-analysis. This was done by applying a quality assessment instrument, containing criteria described by Walsh and Downe (2006) and Campbell and colleagues (2003). This instrument referred to seven stages (Scope and purpose, Design, Sampling strategy, Analysis, Interpretation, Ethical dimensions, Relevance and transferability) incorporating nine 'head items' or 'essential criteria' (Clear statement of and rationale for research question(s) / aim(s) / purpose(s), Study thoroughly contextualised by existing literature, Method / design apparent and consistent with research intent, Data collection strategy apparent and appropriate, Sample and sampling method appropriate, Analytic approach appropriate, Data used to support interpretation, Demonstration of sensitivity to ethical concerns, Relevance and transferability evident) that each included several specific items. We scored each specific item, essential criterion and stage by 'A', 'B' or ' $\mathrm{C}$ ', respectively indicating that an item was properly, partially, or not properly addressed or stated. Articles with 'good quality' were coded by maximum one ' $\mathrm{C}$ ' or two ' $\mathrm{B}$ ' head items; articles with 'moderate quality' by minimum two 'C' or three 'B' head items, or a combination of both; and articles with 'poor quality' by minimum three 'C' head items.

\section{Analysis procedure}

In order to review different biological, psychotherapeutic, and contextual interventions that are applied to reduce challenging behaviour among persons with ID, and to analyse intervention effects and moderating variables, we performed a meta-analysis ${ }^{1}$. A priori, we preferred a random-effects to a fixed-effect meta-analysis, because random-effects models take a between-study variance component as a descriptive index of variation into account; study weights are more balanced under the random-

\footnotetext{
${ }^{1}$ However, combining studies should not be done lightly, considering assumptions behind the use of meta-analysis. The fixed-effect model assumes that the true effect size is the same in all studies, while for random-effects metaanalysis the true effects in the studies are assumed to have been sampled from a distribution of true effects (Borenstein et al. 2009).
} 
effects model assigning less relative weight to large studies; random-effects models provide inferential results referring to a universe of more diverse studies than fixed-effect analyses; and because the width of the confidence intervals calculated by the fixed-effect model tends to imply a greater degree of precision than is actually the case, while analysis based on a random-effects model will generally be more 'conservative' and 'realistic' (Borenstein et al. 2009, Fletcher \& Fletcher 2005, Petitti 1994, Wachter \& Straf 1990, Wang \& Bushman 1999). In our random-effects meta-analysis we allowed for variation of the true effect size between studies, and assumed that the studies in our analysis only represent a random sample of effect sizes that could have been observed (Adèr \& Mellenbergh 1999, Borenstein et al. 2009, Cooper \& Hedges 1994, Kline 2005). Therefore, the summary effect is our estimate of the mean of these effects. In order to conduct the meta-analysis, effect sizes (standardised mean difference $d)^{2}$ and variances were computed for all included studies' intervention effects (Borenstein et al. 2009, Rosenthal 1991). We generated a summary effect (effect size and variance) with a 95\% confidence interval, and measures of heterogeneity (Q-value, Tau-squared, I-squared) (Borenstein et al. 2009, Higgins \& Thompson 2002, Thompson 1994, Thompson \& Sharp 1999). The studies were weighted by study precision in order to minimize both the within-study error and the variation in the true effects across studies: studies that yield more precise estimates of the effect size are assigned more weight (Borenstein et al. 2009, Hedges \& Vevea 1998). Next to that, we assessed the impact of moderating variables through subgroup and meta-regression analysis. The former implied analyses of variance to compare treatment effects across groups concerning categorical variables, while the latter explored the impact of continuous moderators (Borenstein et al. 2009, Egger et al. 2007, Thompson \& Higgins 2002). Furthermore, a sensitivity analysis was performed by running the analysis 30 times, each time removing one study, in order to show each study's impact on the combined effect (Borenstein et al. 2009, Egger et al. 1997a). In addition, we analysed the possible impact of publication bias by a funnel plot-, a fail-safe N-, and Duval's and Tweedie's trim and fillanalysis (Borenstein et al. 2009, Duval \& Tweedie 2000, Egger et al. 1997b, Kulinskaya et al. 2008, Rothstein 2005, Soeken \& Sripusanapan 2003, Sutton et al. 2000b, Thornton \& Lee 2000). The classic fail-safe $\mathrm{N}$ asks whether we need to be concerned that the entire observed effect may be an artifact of bias, while trim and fill offers a more nuanced perspective by asking how the effect size would shift if the apparent bias were to be removed (Borenstein et al. 2009, Cooper 1998, Higgins \& Green 2008, Hunter \& Schmidt 2004, Lewis-Beck et al. 2004, Lipsey \& Wilson 2001, Riegelman 2005, Rothstein 2005, Salovey \& Rothman 2003, Vaughn \& Howard 2009, Wolf 1986). Statistical analyses were conducted using Comprehensive Meta-Analysis Version 2.0 (Borenstein et al. 2009, http://www.metaanalysis.com).

\footnotetext{
${ }^{2}$ The calculation of the standardised mean difference $d$ is based on means and standard deviations, which are not reliable indicators of location and spread for skewed distributions (Larson 2006). Since the included studies did not report measures of skewness, we can not conclude whether more distribution-robust statistics such as medians and interquartile ranges should be used instead of the standardised mean difference (Everitt \& Howell 2005, Larson 2006).
} 


\section{Results}

\section{Description of primary studies and participants}

Guided by the described inclusion and exclusion criteria, 80 articles were considered for inclusion in our study. However, only 30 articles contained sufficient data to enable meta-analysis, and could be entered in the programme Comprehensive Meta-Analysis Version 2.0 (see http://www.metaanalysis.com for a list of all supported formats). Table 1 presents an overview of the 30 selected articles, representing 1444 participants. For each article, challenging behaviours shown by participants, interventions used to target these challenging behaviours, assessment of the articles' quality, and gender, level of ID and number of participants are reported. The references to these articles are drawn up in Appendix 1.

From those 30 articles, 18 described a biological, 13 a psychotherapeutic, and 9 a contextual intervention, with sometimes more than one implemented treatment discussed in a single article. More specific, 14 studies reported a unimodal biological, 5 a unimodal psychotherapeutic, and 2 a unimodal contextual intervention, next to 5 psychotherapeutic-contextual and 2 biological-psychotherapeutic treatments, 1 biological-contextual, and 1 biological-psychotherapeutic-contextual intervention. For the biological treatments, especially atypical antipsychotic medications (risperdone and olanzapine) were studied (9), next to typical antipsychotics (2) and other biological interventions (5). Two articles described sensory interventions. Regarding psychotherapeutic treatments, four behavioural, four systemic, three cognitive-behavioural and two other psychotherapeutic interventions were investigated. Concerning the explored contextual treatments, there were especially interventions situated within a multidisciplinary approach (6) and interventions focusing on changing the environment (2).

Describing methodological features, we looked at designs, data collection instruments, and their reported reliability. The most often implemented study design was an experiment (14), followed by a quasi-experiment (10), and a natural experiment (6). Regarding the data collection procedure, 22 authors applied questionnaires, 11 interviews, 9 tests or experimental measures, 9 observations, and 8 other data collection methods. In 16 articles indices of reliability were reported for data collection instruments. Turning to study characteristics, the length of the research period (the average time between the first and last measurement for each studied group of participants) was less than a year in 13 studies, more than one year in 10 studies, and not mentioned in 7 articles. The continent where most research took place was America (14), followed by Europe (11), Australia (4) and Asia (1). Finally, we recorded four participant features: the number of participants, and their age, gender, and degree of ID. Seven articles described 20 or fewer participants, 12 articles reported on interventions implemented for 21 to 50 participants, and 11 articles reported on intervention effects for more than 50 participants. In 21 studies there were more male than female participants, while for 6 articles the opposite was true. There were slightly more (16) studies describing a mean age of participants above 
18, compared with 11 studies describing a mean age of participants under 18, while 3 articles did not mention participants' ages. Furthermore, 16 studies involved persons with mild ID, 14 moderate ID, 15 severe ID and 8 profound ID. Six articles did not mention the degree of ID of their participants. In grading the quality of the articles, we found that 22 articles were of 'good' and 8 of 'moderate' quality. Especially Scope \& Purpose-, Analysis- and Interpretation-items scored very well. Regarding the categories Design, Sampling and Ethics, there was often information missing.

\section{Meta-analysis}

Combined effect sizes and their standard errors computed for all 30 articles are presented in Table 1. The applied interventions made an improvement in each study: all calculated effect sizes are positive ${ }^{3}$. Applying random-effects weights, the standardised mean difference is 0.671 with a $95 \%$ confidence interval of 0.570 to 0.771 . According to Cohen (1988) this is a medium (effect size around 0.5) to large (effect size around 0.8) effect. The null hypothesis that the mean of these effects is zero, can be rejected, $\mathrm{Z}(N=30)=13.070, p<0.001^{4}$.

In addition, we computed three measures quantifying heterogeneity. First, the $p$-value for the weighted sum of squares on a standardised scale, $\mathrm{Q}=30.277$ with $\mathrm{df}=29$, is 0.400 . Applying 0.05 as criterion for statistical significance, we cannot reject the null hypothesis that all studies share a common effect size. Second, tau-squared, the variance of the true effects calculated on the same scale (squared) as the effects themselves, is 0.003 , with a standard error of 0.021 . Third, I-squared, the proportion of observed dispersion that is real, is $4.219 \%$. This means that $4.219 \%$ of the observed variance comes from real differences between studies, and, as such, can potentially be explained by study-level covariates (Borenstein et al. 2009, Cooper \& Hedges 1994).

A sensitivity analysis was performed to determine the robustness of our results by examining whether our conclusions might differ substantially if a study was dropped (Borenstein et al. 2009, Cooper \& Hedges 1994, Petitti 1994, Sutton et al. 2000a). We calculated for each study the overall standardized mean difference when that study was hypothetically removed from the meta-analysis. Since the 30 overall effect sizes formed by omitting each study separately varied between 0.649 and 0.689 , our results look very robust.

Furthermore, the impact of moderating variables was assessed through subgroup and meta-regression analysis. We applied analyses of variance to compare treatment effects across groups for the following

\footnotetext{
${ }^{3}$ Incidentally, if the null hypothesis of no treatment effect would be true, then there would be a $50 \%$ chance of observing positive effect sizes. Because the studies can be considered as independent events, this setup constitutes a binomial situation with $p=.50$. The probability to observe 30 successes out of 30 trials is $.50^{30}$, or in other words $p$ $<.0001$.

${ }^{4}$ Applying the fixed-effect model, the standardized mean difference is 0.670 with a $95 \%$ confidence interval of 0.572 to 0.768 , and the null hypothesis that the mean of these effects is zero, can be rejected, $\mathrm{Z}(N=30)=13.452, p$ $<0.001$. So, the results for the fixed- and random-effects analysis are analogous.
} 
categorical variables: intervention type (biological, psychotherapeutic and contextual), intervention combination (unimodal, multimodal), quality assessment, study design (experiment, quasi-experiment, natural experiment), data collection (test, questionnaire, observation, interview, other), reliability, length of the research period, continent, and the gender, age, and degree of ID (mild, moderate, severe, profound) of participants. We present the descriptive statistics of these moderators in Appendix 2. After assessing the relationships between subgroup membership and effect size, we conclude for all these variables that differences between groups are not significantly related to the effect size.

Table 1: Characteristics of studies included in the meta-analysis

\begin{tabular}{|c|c|c|c|c|c|c|c|c|c|}
\hline First author & $\begin{array}{l}\text { Year } \\
\text { publi- } \\
\text { shed }\end{array}$ & $\begin{array}{l}\text { Num- } \\
\text { ber of } \\
\text { partici- } \\
\text { pants }\end{array}$ & $\begin{array}{l}\text { Level of } \\
\text { ID * }\end{array}$ & $\begin{array}{l}\text { Male- } \\
\text { female } \\
\text { partici- } \\
\text { pants }\end{array}$ & $\begin{array}{l}\text { Category of } \\
\text { target } \\
\text { challenging } \\
\text { behaviour } * *\end{array}$ & $\begin{array}{l}\text { Inter- } \\
\text { vention } \\
\text { type } \\
* * * \\
\end{array}$ & $\begin{array}{l}\text { Quality } \\
\text { of the } \\
\text { article } \\
* * * *\end{array}$ & $\begin{array}{l}\text { Std diff } \\
\text { in means } \\
* * * * *\end{array}$ & $\begin{array}{l}\text { Standard } \\
\text { error }\end{array}$ \\
\hline Aman & 2002 & 118 & 1,2 & $97-21$ & 1 & B & A & 0.502 & 0.191 \\
\hline Buitelaar & 2001 & 38 & 1 & $33-5$ & 3 & B & A & 0.394 & 0.338 \\
\hline Capone & 2008 & 23 & 3 & $20-3$ & 1,4 & B & A & 0.723 & 0.236 \\
\hline Chan & 2005 & 89 & $1,2,3$ & $36-53$ & 3 & B & A & 0.457 & 0.218 \\
\hline Dowling & 2006 & 56 & $1,2,3$ & . & 1,2 & $\mathrm{PC}$ & $\mathrm{A}$ & 0.662 & 0.279 \\
\hline Duker & 2000 & 16 & . & $10-6$ & 4 & $\mathrm{P}$ & B & 1.207 & 0.544 \\
\hline Gates & 2001 & 77 & . & . & 1 & $\mathrm{PC}$ & A & 0.187 & 0.256 \\
\hline Holden & 2000 & 28 & 1 & $17-11$ & 1 & BPC & B & 0.814 & 0.285 \\
\hline Huang & 2007 & 40 & . & $14-26$ & 1 & $\mathrm{BP}$ & B & 0.730 & 0.179 \\
\hline Hudson & 2003 & 115 & $1,2,3$ & $81-34$ & 1 & $\mathrm{PC}$ & A & 0.482 & 0.257 \\
\hline Janowsky & 2003 & 22 & 3,4 & $8-14$ & $1,3,4$ & B & B & 0.567 & 0.305 \\
\hline Janowsky & 2005 & 34 & 3,4 & $23-11$ & 3,4 & B & A & 0.845 & 0.350 \\
\hline Janowsky & 2003 & 20 & $1,2,3,4$ & $9-11$ & $1,3,4$ & B & $\mathrm{A}$ & 1.380 & 0.570 \\
\hline Mace & 2001 & 15 & 3,4 & $10-5$ & 4 & $\mathrm{BP}$ & A & 0.269 & 0.488 \\
\hline McDonough & 2000 & 7 & 3,4 & $5-2$ & 4 & B & B & 0.769 & 0.434 \\
\hline Packman & 2003 & 24 & . & $18-6$ & 1 & $\mathrm{P}$ & A & 0.548 & 0.416 \\
\hline Pearson & 2003 & 24 & 1,2 & $18-6$ & 1,3 & B & B & 0.417 & 0.293 \\
\hline Plant & 2007 & 74 & $1,2,3$ & $55-19$ & 1 & $\mathrm{PC}$ & A & 0.752 & 0.172 \\
\hline Read & 2007 & 24 & $2,3,4$ & $19-5$ & 3,4 & B & B & 0.708 & 0.234 \\
\hline Roberts & 2006 & 47 & 1 & $37-10$ & 1 & $\mathrm{PC}$ & A & 0.855 & 0.308 \\
\hline Rose & 2000 & 44 & . & $39-5$ & 3 & $\mathrm{P}$ & A & 1.411 & 0.340 \\
\hline Rose & 2005 & 86 & . & $71-15$ & 3 & $\mathrm{P}$ & A & 1.109 & 0.234 \\
\hline Shapira & 2004 & 8 & 1,2 & $3-5$ & 4 & B & A & 1.158 & 0.460 \\
\hline Singh & 2004 & 45 & 3,4 & $31-14$ & 3,4 & $\mathrm{BC}$ & B & 1.075 & 0.336 \\
\hline Snyder & 2002 & 110 & 1,2 & $83-27$ & 1,3 & B & A & 0.659 & 0.197 \\
\hline Taylor & 2002 & 19 & 1 & $19-0$ & 3 & $\mathrm{P}$ & A & 1.306 & 0.509 \\
\hline Turgay & 2002 & 77 & 1,2 & $57-20$ & 1 & B & A & 0.223 & 0.308 \\
\hline Xenitidis & 2004 & 84 & $1,2,3$ & $36-48$ & 1,2 & $\mathrm{C}$ & $\mathrm{A}$ & 0.703 & 0.195 \\
\hline Young & 2006 & 60 & 2,3 & $38-22$ & 1 & $\mathrm{C}$ & A & 0.182 & 0.259 \\
\hline Zarcone & 2001 & 20 & $1,2,3,4$ & $10-10$ & 1 & B & A & 0.867 & 0.468 \\
\hline
\end{tabular}

Missing information is depicted as '.'

*: 1 =mild; $2=$ moderate; $3=$ severe; $4=$ profound

**: $1=$ aberrant/challenging/disruptive/maladaptive behaviour; $2=$ psychiatric disorders, psychotic symptoms; $3=$ aggression, destructive behaviour, anger; 4=self-injurious behaviour; $5=$ sexual offending; $6=$ stereotypical, repetitive behaviour

***: $\mathrm{B}=\mathrm{Biological}$ intervention; $\mathrm{P}=\mathrm{Psychotherapeutic}$ intervention; $\mathrm{C}=$ Contextual intervention; $\mathrm{BP}=\mathrm{Biological}-$ Psychotherapeutic intervention; $\mathrm{PC}=$ Psychotherapeutic-Contextual intervention; $\mathrm{BC}=\mathrm{Biological}-\mathrm{Contextual}$ intervention; $\mathrm{BPC}=$ Biological-Psychotherapeutic-Contextual intervention

$* * * *: \mathrm{A}=$ article with good quality; $\mathrm{B}=$ article with moderate quality

*****: Standardised difference in means

In addition, we explored the impact of one continuous moderator: the year of publication. For this moderator too, we cannot reject the null hypothesis of no effect. Applying the regression model (unrestricted maximum likelihood), we see that the total dispersion of studies about the grand mean 
(Q-total) is 30.27744 with $\mathrm{p}=0.40025(\mathrm{df}=29)$, meaning that the amount of total variance is less than we would expect based on the within-study error. Furthermore, the dispersion explained by the covariates (Q-model) is 0.26403 with $\mathrm{p}=0.60737(\mathrm{df}=1)$, which means that the relationship between publication year and treatment effect is even weaker than we would expect by chance.

Finally, we address possible publication bias effects by a funnel plot-, a fail-safe N-, and Duval's and Tweedie's trim and fill-analysis. We refer to publication bias when studies included in an analysis differ systematically from all studies that could be included: particularly, studies with larger effects are more likely to be published, and this can lead to an upward bias in the summary effect (Borenstein et al. 2009, Cooper \& Hedges 1994, Higgins \& Green 2008, Hunter \& Schmidt 2004, Lipsey \& Wilson 2001). First, we explore possible publication bias effects by a funnel plot. In Figure 1 a measure of study size (precision, the inverse of standard error) is plotted on the vertical axis as a function of effect size on the horizontal axis. In the absence of publication bias, we would expect the included studies (white circles in Figure 1) to be distributed symmetrically around the combined effect size (Adèr \& Mellenbergh 1999, Borenstein et al. 2009, Bowling \& Ebrahim 2006, Petitti 1994, Rothstein 2005), and this seems to be the case for our meta-analysis.

In the following, we assess some statistical procedures to quantify this possible publication bias effect. The fail-safe $\mathrm{N}$ is 1336, meaning that we would need to locate and include 1336 'null' studies in order for the combined two-tailed $p$-value to exceed 0.050. Because this number is large, we can be relatively confident that the treatment effect, while possibly inflated by the exclusion of some studies, is real. Duval and Tweedie's trim and fill analysis addressing the left side of the mean effect suggests that four studies are missing. These four imputed studies are plotted in Figure 1. Under the randomeffects model the standardised mean difference and $95 \%$ confidence interval for the combined studies is $0.67070(0.57012,0.77128)$. Using trim and fill, the imputed standardised mean difference is $0.63436(0.52493,0.74378)$, which is a little bit lower than our standardised mean difference. When addressing Duval and Tweedie's trim and fill to the right side of the mean effect, the method suggests that no studies are missing. 


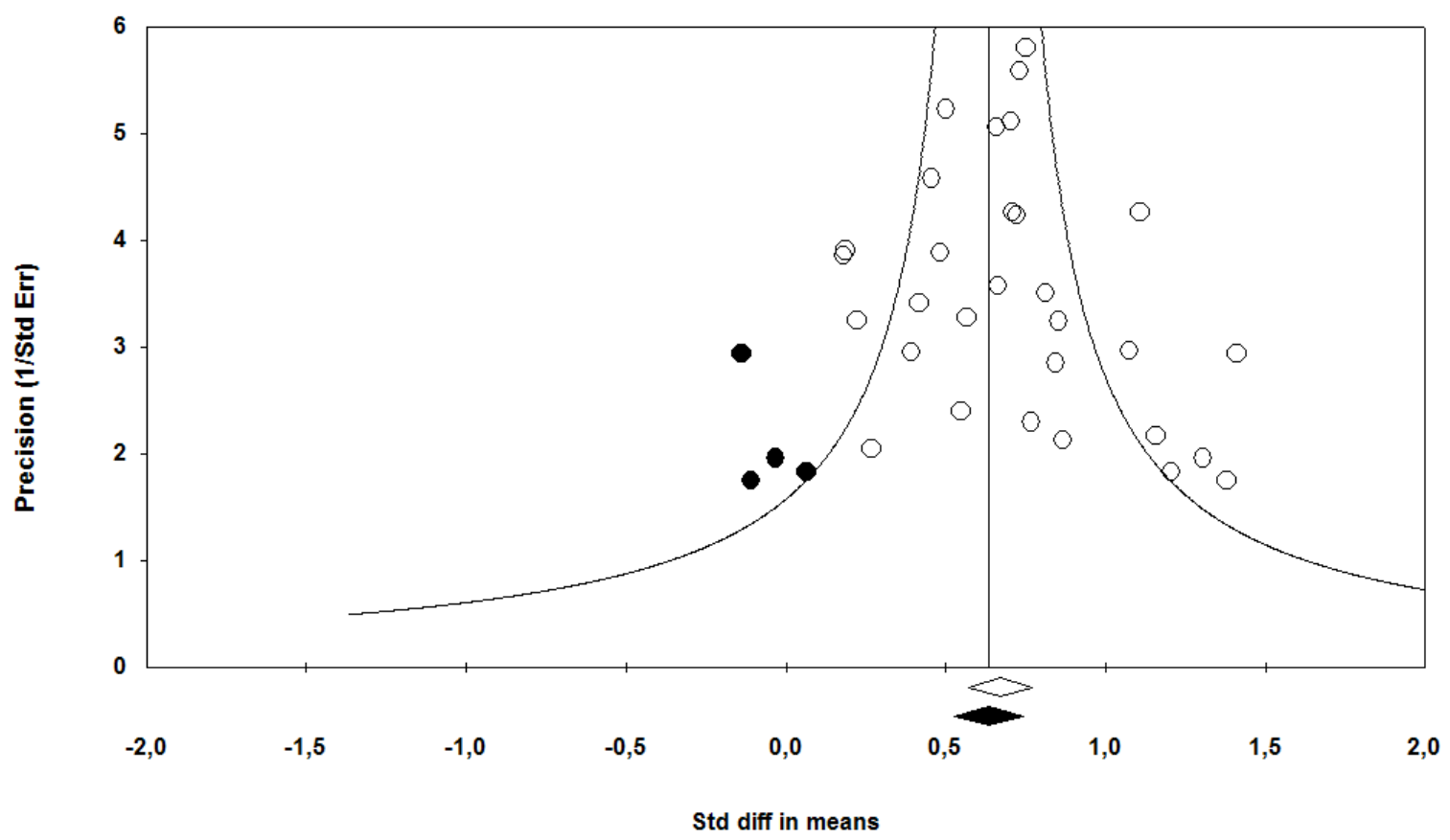

Figure 1: Funnel plot of precision by standardised difference in means: plot with observed (white circles) and imputed (black circles) studies

So, after applying a funnel plot-, a fail-safe N-, and Duval's and Tweedie's trim and fill-analysis, we conclude that our meta-analysis does not seem to suffer much from publication bias effects.

\section{Discussion}

In this meta-analysis of articles describing rigorous quantitative empirical studies of intervention effects on challenging behaviour among persons with ID we found effect sizes (standardised mean differences) from 0.223 to 1.411 . So, the effect sizes vary between a small and a very large effect (Cohen 1988), all indicating positive treatment effects. The combined effect size over all studies is 0.671 , with a $95 \%$ confidence interval of 0.570 to 0.771 , which is a medium to large effect according to Cohen (1988). The implemented sensitivity analysis revealed that this effect is robust. Analyses of variance showed no significant different treatment effects for biological, psychotherapeutic, and contextual interventions. Differences between unimodal and multimodal treatments turned out to be not significant as well. The reported means and standard errors for the moderators intervention type and intervention combination show that there are only small differences between the mean effects for biological, psychotherapeutic, and contextual interventions, and for unimodal and multimodal treatments (Appendix 2).

In the general literature and in articles presenting qualitative and descriptive material, some authors claim that there is evidence for the effectiveness of pharmacological treatments (Deb et al. 2007, Grey \& Hastings 2005), although many authors assert that they lack empirical effectiveness (Antonacci et 
al. 2008, Brylewski \& Duggan 1999, La Malfa et al. 2006, Matson \& Neal 2009, Sohanpal et al. 2007, Taylor 2002, Thomson et al. 2009a, 2009b). Besides, there are many concerns regarding their adverse effects (Deb et al. 2007, McGillivray \& McCabe 2006, Sohanpal et al. 2007). Concerning psychotherapeutic and contextual interventions too, there are authors advocating their effectiveness (Ager \& O’May 2001, Beail 2003, Campbell 2003, Didden et al. 2006, Gavidia-Payne \& Hudson 2002, Grey \& Hastings 2005, Harvey et al. 2009, Mildon et al. 2008, Moss et al. 1997, Prout \& Nowak-Drabik 2003, Shogren et al. 2004), while some say that the evidence is rather limited (Antonacci et al. 2008, Gustafsson et al. 2009, Sturmey 2004, Taylor 2005, Willner 2005). Our metaanalysis shows that there is evidence for the effectiveness of pharmacological, psychotherapeutic and contextual interventions, used alone or in combination. Furthermore, we found no indications for the superiority of one of the treatment approaches or combination types.

Treatment effects also did not vary much across groups for the categorical moderators included in our meta-analysis: quality assessment, study design, data collection, reliability, length of the research period, continent, and gender, age, and level of ID of participants. We also did not find any effect of the continuous moderator publication year on the treatment effect. Some authors have suggested that the nonsignificance of moderator effects is not uncommon, due to low statistical power for detecting interaction between a moderator variable and the independent variable (Aguinis \& Beaty 2005, Aguinis \& Stone-Romero 1997, Borenstein et al. 2009, Hedges \& Pigott 2001, 2004, Shieh 2009). For our meta-analysis, we see in Appendix 2 that there exist only small differences between the mean effects for the tested categorical moderating variables, so even if we would increase the power, we would most likely not detect clinically important differences. As a particular strength of our study we want to mention that a funnel plot-, a fail-safe N-, and Duval's and Tweedie's trim and fill-analysis demonstrate that our meta-analysis does not seem to suffer much from publication bias effects.

In summary, interventions for challenging behaviour among persons with ID described in the 30 included articles were effective, with only small differences between the mean effects for biological, psychotherapeutic, and contextual treatments, and for unimodal and multimodal interventions. In contrast to claims in the literature that the evidence for one or another intervention is still rather limited, the effects in our meta-analysis were robust and convincing.

Further research should now focus on the working mechanisms of these successful interventions. We showed that challenging behaviour among individuals with ID can be successfully treated by diverse biological, psychotherapeutic, and contextual interventions, but it is still not very clear how and why each of these interventions works, either when applied alone or combined. Are there common working mechanisms behind these interventions, or do biological, psychotherapeutic, and contextual interventions function differently? And, how do they work combined? To this end, it would be interesting to have more longitudinal research focusing on differential effects of biological, psychotherapeutic, and contextual interventions, taking into account theoretically relevant moderators and mediators. 


\section{References}

Adèr H.J. \& Mellenbergh G.J. (Eds.) (1999) Research methodology in the social, behavioural and life sciences: Design, models and methods. Sage, London.

Ager A. \& O'May F. (2001) Issues in the definition and implementation of "best practice" for staff delivery of interventions for challenging behaviour. Journal of Intellectual \& Developmental Disability 26, 243-256.

Aguinis H. \& Beaty J.C. (2005) Effect size and power in assessing moderating effects of categorical variables using multiple regression: A 30-year review. Journal of Applied Psychology 90, 94-107.

Aguinis H. \& Stone-Romero E.F. (1997) Methodological artifacts in moderated multiple regression and their effects on statistical power. Journal of Applied Psychology 82, 192-206.

Allen D. (2000) Recent research on physical aggression in persons with intellectual disability: An overview. Journal of Intellectual \& Developmental Disability 25, 41-57.

Allen D. \& Davies D. (2007) Challenging behaviour and psychiatric disorder in intellectual disability. Current Opinion in Psychiatry 20, 450-455.

Altman D.G., Schulz K.F., Moher D., Egger M., Davidoff F., Elbourne D. et al. (2001) The revised CONSORT statement for reporting randomized trials: Explanation and elaboration. Annals of Internal Medicine 134, 663694.

Antonacci D.J., Manuel C. \& Davis E. (2008) Diagnosis and treatment of aggression in individuals with developmental disabilities. Psychiatry Quarterly 79, 225-247.

Aunos M., Feldman M. \& Goupil G. (2008) Mothering with intellectual disabilities: Relationship between social support, health and well-being, parenting and child behaviour outcomes. Journal of Applied Research in Intellectual Disabilities 21, 320-330.

Beail N. (2003) What works for people with mental retardation? Critical commentary on cognitive-behavioural and psychodynamic psychotherapy research. Mental Retardation 41, 468-472.

Benson B.A. \& Brooks W.T. (2008) Aggressive challenging behaviour and intellectual disability. Current Opinion in Psychiatry 21, 454-458.

Blacher J. \& McIntyre L.L. (2006) Syndrome specificity and behavioural disorders in young adults with intellectual disability: Cultural differences in family impact. Journal of Intellectual Disability Research 50, 184198.

Borenstein M., Hedges L.V., Higgins J. \& Rothstein H. (2009) Introduction to meta-analysis. Wiley, Chichester. Borthwick-Duffy S.A. (1994) Epidemiology and prevalence of psychopathology in people with mental retardation. Journal of Consulting and Clinical Psychology 62, 17-27.

Bouras N. (1999) Psychiatric and behavioural disorders in developmental disabilities and mental retardation. Cambridge University Press, Cambridge.

Bowling A. \& Ebrahim S. (2006) Handbook of health research methods: Investigation, measurement and analysis. Open University Press, Maidenhead.

Bradley E.A., Summers J.A., Wood H.L. \& Bryson S.E. (2004) Comparing rates of psychiatric and behaviour disorders in adolescents and young adults with severe intellectual disability with and without autism. Journal of Autism and Developmental Disorders 34, 151-161.

Brylewski J. \& Duggan L. (1999) Antipsychotic medication for challenging behaviour in people with intellectual disability: A systematic review of randomized controlled trials. Journal of Intellectual Disability Research 43, 360-371.

Campbell J.M. (2003) Efficacy of behavioural interventions for reducing problem behaviour in persons with autism: A quantitative synthesis of single-subject research. Research in Developmental Disabilities 24, 120-138. Campbell R., Pound P., Pope C., Britten N., Pill R., Morgan M. et al. (2003) Evaluating metaethnography: A synthesis of research on lay experiences of diabetes and diabetes care. Social Science \& Medicine 56, 671-684. Chadwick O., Kusel Y. \& Cuddy M. (2008) Factors associated with the risk of behaviour problems in adolescents with severe intellectual disabilities. Journal of Intellectual Disability Research 52, 864-876.

Cohen J. (1988) Statistical power analysis for the behavioral sciences (2nd Ed.). Erlbaum, Hillsdale.

Collacott R.A., Cooper S.A., Branford D. \& McGrother C. (1998) Epidemiology of self-injurious behaviour in adults with learning disabilities. British Journal of Psychiatry 173, 428-432.

Comprehensive Meta-Analysis Version 2.0 (2009) http://www.meta-analysis.com.

Cooper H. (1998) Synthesizing research: A guide for literature reviews ( $3^{\text {rd }}$ Ed.). Sage, London.

Cooper H. \& Hedges L.V. (1994) The handbook of research synthesis. Russell Sage Foundation, New York.

Cooper S.A., Smiley E., Allan L.M., Jackson A., Finlayson J., Mantry D. et al. (2009a) Adults with intellectual disabilities: Prevalence, incidence and remission of self-injurious behaviour, and related factors. Journal of Intellectual Disability Research 53, 200-216.

Cooper S.A., Smiley E., Finlayson J., Jackson A., Allan L., Williamson A. et al. (2007) The prevalence, incidence, and factors predictive of mental ill-health in adults with profound intellectual disabilities. Journal of Applied Research in Intellectual Disabilities 20, 493-501. 
Cooper S.A., Smiley E., Jackson A., Finlayson J., Allan L.M., Mantry D. et al. (2009b) Adults with intellectual disabilities: Prevalence, incidence and remission of aggressive behaviour and related factors. Journal of Intellectual Disability Research 53, 217-232.

Cormack K.F.M., Brown A.C. \& Hastings R.P. (2000) Behavioural and emotional difficulties in students attending schools for children and adolescents with severe intellectual disability. Journal of Intellectual Disability Research 44, 124-129.

Crocker A.G., Mercier C., Allaire J.-F. \& Roy M.E. (2007) Profiles and correlates of aggressive behaviour among adults with intellectual disabilities. Journal of Intellectual Disability Research 51, 786-801.

Crocker A.G., Mercier C., Lachapelle Y., Brunet A., Morin D. \& Roy M.E. (2006) Prevalence and types of aggressive behaviour among adults with intellectual disabilities. Journal of Intellectual Disability Research 50, 652-661.

Danquah A., Limb K., Chapman M., Burke C., Flood A., Gore S. et al. (2009) An investigation of factors predictive of continued self-injurious behaviour in an intellectual disability service. Journal of Applied Research in Intellectual Disabilities 22, 395-399.

de Ruiter K.P., Dekker M.C., Douma J.C.H., Verhulst F.C. \& Koot H.M. (2008) Development of parent- and teacher-reported emotional and behavioural problems in young people with intellectual disabilities: Does level of intellectual disability matter? Journal of Applied Research in Intellectual Disabilities 21, 70-80.

Deb S., Sohanpal S.K., Soni R., Len-o Tre L. \& Unwin G. (2007) The effectiveness of antipsychotic medication in the management of behaviour problems in adults with intellectual disabilities. Journal of Intellectual Disability Research 51, 766-777.

Deb S., Thomas M. \& Bright C. (2001) Mental disorder in adults with intellectual disability. The rate of behaviour disorders among a community-based population aged between 16 and 64 years. Journal of Intellectual Disability Research 45, 506-514.

Dekker M.C., Koot H.M., van der Ende J. \& Verhulst F.C. (2002) Emotional and behavioural problems in children and adolescents with and without intellectual disability. Journal of Child Psychology and Psychiatry 43, 1087-1098.

Didden R., Korzilius H. \& Curfs L.M.G. (2007) Skin-picking in individuals with Prader-Willi syndrome: Prevalence, functional assessment, and its comorbidity with compulsive and self-injurious behaviours. Journal of Applied Research in Intellectual Disabilities 20, 409-419.

Didden R., Korzilius H., van Oorsouw W. \& Sturmey P. (2006) Behavioural treatment of challenging behaviours in individuals with mild mental retardation: Meta-analysis of single-subject research. American Journal on Mental Retardation 111, 290-298.

Dösen A. \& Day K. (2001) Treating mental illness and behaviour disorders in children and adults with mental retardation. American Psychiatric Publications, Washington.

Duval S. \& Tweedie R. (2000) Trim and fill: A simple funnel-plot-based method of testing and adjusting for publication bias in meta-analysis. Biometrics 56, 455-463.

Egger M., Smith G.D. \& Altman D.G. (2007) Systematic reviews in health care: Meta-analysis in context. BMJ, London.

Egger M., Smith G.D. \& Philips A.N. (1997a) Meta-analysis: Principles and procedures. British Medical Journal 315, 1533-1537.

Egger M., Smith G.D., Schneider M. \& Minder C. (1997b) Bias in meta-analysis detected by a simple, graphical test. British Medical Journal 315, 629-634.

Embregts P.J.C.M., Didden R., Huitink C. \& Schreuder N. (2009) Contextual variables affecting aggressive behaviour in individuals with mild to borderline intellectual disabilities who live in a residential facility. Journal of Intellectual Disability Research 53, 255-264.

Emerson E., Kiernan C., Alborz A., Reeves D., Mason H. \& Swarbrick R. et al. (2001) The prevalence of challenging behaviors: A total population study. Research in Developmental Disabilities 22, 77-93.

Everitt B.S. \& Howell D.C. (Eds.) (2005) Encyclopedia of statistics in behavioral science. Wiley, Chichester. Fletcher R.H. \& Fletcher S.W. (2005) Clinical epidemiology: The essentials. Williams and Wilkins, Baltimore. Gavidia-Payne S. \& Hudson A. (2002) Behavioural supports for parents of children with an intellectual disability and problem behaviours: An overview of the literature. Journal of Intellectual \& Developmental Disability 27, 31-55.

Grey I.M. \& Hastings R.P. (2005) Evidence-based practices in intellectual disability and behaviour disorders. Current Opinion in Psychiatry 18, 469-475.

Gustafsson C., Ojehagen A., Hansson L., Sandlund M., Nystrom M., Glad J. et al. (2009) Effects of psychosocial interventions for people with intellectual disabilities and mental health problems. Research on Social Work Practice 19, 281-290.

Harvey S.T., Boer D., Meyer L.H. \& Evans I.M. (2009) Updating a meta-analysis of intervention research with challenging behaviour: Treatment validity and standards of practice. Journal of Intellectual \& Developmental Disability 34, 67-80. 
Hassiotis A., Parkes C., Jones L., Fitzgerald B. \& Romeo R. (2008) Individual characteristics and service expenditure on challenging behaviour for adults with intellectual disabilities. Journal of Applied Research in Intellectual Disabilities 21, 438-445.

Hastings R.P. \& Mount R.H. (2001) Early correlates of behavioural and emotional problems in children and adolescents with severe intellectual disabilities: A preliminary study. Journal of Applied Research in Intellectual Disabilities 14, 381-391.

Hedges L.V. \& Pigott T.D. (2001) The power of statistical tests in meta-analysis. Psychological Methods 6, 203217.

Hedges L.V. \& Pigott T.D. (2004) The power of statistical tests for moderators in meta-analysis. Psychological Methods 9, 426-445.

Hedges L.V. \& Vevea J.L. (1998) Fixed- and random-effects models in meta-analysis. Psychological Methods 3 , 486-504.

Hemmings C.P., Gravestock S., Pickard M. \& Bouras N. (2006) Psychiatric symptoms and problem behaviour in people with intellectual disabilities. Journal of Intellectual Disability Research 50, 269-276.

Higgins J.P.T. \& Green S. (2008) Cochrane handbook for systematic reviews of interventions. John Wiley and Sons, Chichester.

Higgins J.P.T. \& Thompson S.G. (2002) Quantifying heterogeneity in a meta-analysis. Statistics in Medicine 21, 1539-1558.

Holden B. \& Gitlesen J.P. (2009) The overlap between psychiatric symptoms and challenging behaviour: A preliminary study. Research in Developmental Disabilities 30, 210-218.

Hunter J.E. \& Schmidt F.L. (2004) Methods of meta-analysis: Correcting error and bias in research findings $\left(2^{\text {nd }}\right.$ Ed.). Sage, Thousand Oaks.

Jadad A.R., Moore R.A., Carroll D., Jenkinson C., Reynolds D.J.M., Gavaghan D.J. et al. (1996) Assessing the quality of reports of randomized clinical trials: Is blinding necessary? Controlled Clinical Trials 17, 1-12.

Janssen C.G.C., Schuengel C. \& Stolk J. (2002) Understanding challenging behaviour in people with severe and profound intellectual disability: A stress-attachment model. Journal of Intellectual Disability Research 46, 445453.

Kahng S., Iwata B.A. \& Lewin A.B. (2002) Behavioural treatment of self-injury, 1964 to 2000. American Journal on Mental Retardation 107, 212-221.

Khan K.S., Riet G., Popay J., Nixon J. \& Kleijnen J. (2001) Study quality assessment (phase 5): Conducting the review (stage 2). Undertaking systematic reviews of research on effectiveness. CRD Report 4, 1-20.

Kline, R.B. (2005) Principles and practice of structural equation modeling. Guilford, New York.

Knapp M., Comas-Herrera A., Astin J., Beecham J. \& Pendaries C. (2005) Intellectual disability, challenging behaviour and cost in care accommodation: What are the links? Health and Social Care in the Community 13, 297-306

Kulinskaya E., Morgenthaler S. \& Staudte R.G. (2008) Meta analysis: A guide to calibrating and combining statistical evidence. Wiley, Chichester.

La Malfa G., Lassi S., Bertelli M. \& Castellani A. (2006) Reviewing the use of antipsychotic drugs in people with intellectual disability. Human Psychopharmacology - Clinical and Experimental 21, 73-89.

Larson M.G. (2006) Descriptive statistics and graphical displays. Circulation 114, 76-81.

Lewis-Beck M.S., Bryman A. \& Liao T.F. (2004) The Sage encyclopedia of social science research methods. Sage, Thousand Oaks.

Lipsey M.W. \& Wilson D.B. (2001) Practical meta-analysis. Sage, Thousand Oaks.

Lotan M. \& Gold C. (2009) Meta-analysis of the effectiveness of individual intervention in the controlled multisensory environment (snoezelen) for individuals with intellectual disability. Journal of Intellectual \& Developmental Disability 34, 207-215.

Lowe K., Felce D., Perry J., Baxter H. \& Jones E. (1998) The characteristics and residential situations of people with severe intellectual disability and the most severe challenging behaviour in Wales. Journal of Intellectual Disability Research 42, 375-389.

Matson J.L. \& Boisjoli J.A. (2009) Restraint procedures and challenging behaviours in intellectual disability: An analysis of causative factors. Journal of Applied Research in Intellectual Disabilities 22, 111-117.

Matson J.L. \& Neal D. (2009) Psychotropic medication use for challenging behaviors in persons with intellectual disabilities: An overview. Research in Developmental Disabilities 30, 527-586.

Matson J.L. \& Rivet T.T. (2008) Characteristics of challenging behaviours in adults with autistic disorder, PDDNOS, and intellectual disability. Journal of Intellectual \& Developmental Disability 33, 323-329.

McClintock K., Hall S. \& Oliver C. (2003) Risk markers associated with challenging behaviours in people with intellectual disabilities: A meta-analytic study. Journal of Intellectual Disability Research 47, 405-416.

McGillivray J.A. \& McCabe M.P. (2006) Emerging trends in the use of drugs to manage the challenging behaviour of people with intellectual disability. Journal of Applied Research in Intellectual Disabilities 19, 163172 . 
McIntyre L.L., Blacher J. \& Baker B.L. (2002) Behaviour/mental health problems in young adults with intellectual disability: The impact on families. Journal of Intellectual Disability Research 46, 239-249.

Mildon R., Wade C. \& Matthews J. (2008) Considering the contextual fit of an intervention for families headed by parents with an intellectual disability: An exploratory study. Journal of Applied Research in Intellectual Disabilities 21, 377-387.

Moss S., Emerson E., Bouras N. \& Holland A. (1997) Mental disorders and problematic behaviours in people with intellectual disability: Future directions for research. Journal of Intellectual Disability Research 41, 440447.

Murphy G.H., Beadle-Brown J., Wing L., Gould J., Shah A. \& Holmes N. (2005) Chronicity of challenging behaviours in people with severe intellectual disabilities and/or autism: A total population sample. Journal of Autism and Developmental Disorders 35, 405-418.

Oxman A.D. \& Guyatt G.H. (1988) Guidelines for reading literature reviews. Canadian Medical Association Journal 138, 697-703.

Petitti D.B. (1994) Meta-analysis, decision analysis, and cost-effectiveness analysis: Methods for quantitative synthesis in medicine. Oxford University Press, New York.

Prout H.T. \& Nowak-Drabik K.M. (2003) Psychotherapy with persons who have mental retardation: An evaluation of effectiveness. American Journal on Mental Retardation 108, 82-93.

Riegelman R.K. (2005) Studying a study and testing a test: How to read the medical evidence. Lippincott Williams and Wilkins, Philadelphia.

Rosenthal R. (1991) Meta-analytic procedures for social research. Sage, Newbury Park.

Rothstein H.R. (Ed.) (2005) Publication bias in meta-analysis: Prevention, assessment and adjustments. Wiley, Chichester.

Salovey P. \& Rothman A.J. (2003) Social psychology of health. Psychology Press, Hove.

Shadish W.R., Cook T.D. \& Campbell D.T. (2002) Experimental and quasi-experimental designs for generalized causal inference. Houghton Mifflin, Boston.

Shieh G. (2009) Detecting interaction effects in moderated multiple regression with continuous variables power and sample size considerations. Organizational Research Methods 12, 510-528.

Shogren K.A., Faggella-Luby M.N., Bae S.J. \& Wehmeyer M.L. (2004) The effect of choice-making as an intervention for problem behavior: A meta-analysis. Journal of Positive Behavior Interventions 6, 228-237.

Soeken K.L. \& Sripusanapan A. (2003) Assessing publication bias in meta-analysis. Nursing Research 52, 57 60 .

Sohanpal S.K., Deb S., Thomas C., Soni R., Lenôtre L. \& Unwin G. (2007) The effectiveness of antidepressant medication in the management of behaviour problems in adults with intellectual disabilities: A systematic review. Journal of Intellectual Disability Research 51, 750-765.

Sturmey P. (2004) Cognitive therapy with people with intellectual disabilities: A selective review and critique. Clinical Psychology and Psychotherapy 11, 222-232.

Sutton A.J., Abrams K.R., Jones D.R., Sheldon T.A. \& Song F. (2000a) Methods for meta-analysis in medical research. Wiley, Chichester.

Sutton A.J., Song F., Gilbody S.M. \& Abrams K.R. (2000b) Modelling publication bias in meta-analysis: A review. Statistical Methods in Medical Research 9, 421-445.

Taylor J.L. (2002) A review of the assessment and treatment of anger and aggression in offenders with intellectual disability. Journal of Intellectual Disability Research 46, 57-73.

Taylor J.L. (2005) In support of psychotherapy for people who have mental retardation. Mental Retardation 43, 450-453.

Tenneij N.H. \& Koot H.M. (2008) Incidence, types and characteristics of aggressive behaviour in treatment facilities for adults with mild intellectual disability and severe challenging behaviour. Journal of Intellectual Disability Research 52, 114-124.

Thompson S.G. (1994) Systematic Review: Why sources of heterogeneity in meta-analysis should be investigated. British Medical Journal 309, 1351-1355.

Thompson S.G. \& Higgins J.P.T. (2002) How should meta-regression analyses be undertaken and interpreted? Statistics in Medicine 15, 1559-1573.

Thompson S.G. \& Sharp S.J. (1999) Explaining heterogeneity in meta-analysis: A comparison of methods. Statistics in Medicine 18, 2693-2708.

Thomson A., Maltezos S., Paliokosta E. \& Xenitidis K. (2009a) Amfetamine for attention-deficit hyperactivity disorder in people with intellectual disabilities. Cochrane Database of Systematic Reviews 1, CD007009.

Thomson A., Maltezos S., Paliokosta E. \& Xenitidis K. (2009b) Risperdone for attention-deficit hyperactivity disorder in people with intellectual disabilities. Cochrane Database of Systematic Reviews 2, CD007011.

Thornton A. \& Lee P. (2000) Publication bias in meta-analysis: Its causes and consequences. Journal of Clinical Epidemiology 53, 207-216. 
Totsika V. \& Hastings R.P. (2009) Persistent challenging behaviour in people with an intellectual disability. Current Opinion in Psychiatry 22, 437-44.

van Tulder M.W., Furlan A., Bombardier C., Bouter L. \& the Editorial Board of the Cochrane Collaboration Back Review Group (2003) Updated method guidelines for systematic reviews in the Cochrane Collaboration Back Review Group. Spine 28, 1290-1299.

Vaughn M.G. \& Howard M.O. (2009) Readings in evidence-based social work: Syntheses of the intervention knowledge base. Sage, Thousand Oaks.

Verhagen A.P., de Vet H.C.W., de Bie R.A., Kessels A.G.H., Boers M., Bouter L.M. et al. (1998) The Delphi list: A criterial list for quality assessment of randomized clinical trials for conducting systematic reviews developed by Delphi consensus. Journal of Clinical Epidemiology 51, 1234-1251.

Wachter K.W. \& Straf M.L. (1990) The future of meta-analysis. Russell Sage Foundation, New York.

Walsh D. \& Downe S. (2006) Appraising the quality of research. Midwifery 22, 108-119.

Wang M.C. \& Bushman B.J. (1999) Integrating results through meta-analysis review using SAS software. SAS Institute, Cary.

Willner P. (2005) The effectiveness of psychotherapeutic interventions for people with learning disabilities: A critical overview. Journal of Intellectual Disability Research 49, 73-85.

Wolf F.M. (1986) Meta-analysis: Quantitative methods for research synthesis. Sage, Beverly Hills. 


\section{Appendix 1: Articles included in the meta-analysis}

Aman M.G., De Smedt G., Derivan A., Lyons B. \& Findling R.L. (2002) Risperidone disruptive behaviour study group. Double-blind, placebo-controlled study of risperidone for the treatment of disruptive behaviours in children with subaverage intelligence. American Journal of Psychiatry 159, 1337-1346.

Buitelaar J.K., van der Gaag R.J., Cohen-Kettenis P. \& Melman C.T.M. (2001) A randomized controlled trial of risperidone in the treatment of aggression in hospitalized adolescents with subaverage cognitive abilities. Journal of Clinical Psychiatry 62, 239-248.

Capone G.T., Goyal P., Grados M., Smith B. \& Kammann H. (2008) Risperidone use in children with Down syndrome, severe intellectual disability, and comorbid autistic spectrum disorders. A naturalistic study. Journal of Developmental \& Behavioural Pediatrics 29, 106-116.

Chan S., Fung M.Y., Tong C.W. \& Thompson D. (2005) The clinical effectiveness of a multisensory therapy on clients with developmental disability. Research in Developmental Disabilities 26, 131-142.

Dowling S., Hubert J., White S. \& Hollins S. (2006) Bereaved adults with intellectual disabilities. A combined randomized controlled trial and qualitative study of two community-based interventions. Journal of Intellectual Disability Research 50, 277-287.

Duker P.C. \& Seys D.M. (2000) A quasi-experimental study on the effect of electrical aversion treatment on imposed mechanical restraint for severe self-injurious behaviour. Research in Developmental Disabilities 21, 235-242.

Gates B., Newell R. \& Wray J. (2001) Behaviour modification and gentle teaching workshops. Management of children with learning disabilities exhibiting challenging behaviour and implications for learning disability nursing. Journal of Advanced Nursing 34, 86-95.

Holden P. \& Neff J.A. (2000) Intensive outpatient treatment of persons with mental retardation and psychiatric disorder. A preliminary study. Mental Retardation 38, 27-32.

Huang W.H., O'Brien H.R.C., Kalinowski C.M., Vreeland R.G., Kleinbub L. \& Hall G.A. (2007) Multidisciplinary approach to optimizing pharmacological and behavioural interventions for persons with developmental disabilities who are on psychotropic medications. Journal of Developmental and Physical Disabilities 19, 237-250.

Hudson A.M., Matthews J.M., Gavidia-Payne S.T., Cameron C.A., Mildon R.L., Radler G.A. et al. (2003) Evaluation of an intervention system for parents of children with intellectual disability and challenging behaviour. Journal of Intellectual Disability Research 47, 238-249.

Janowsky D.S., Barnhill L.J. \& Davis J.M. (2003b) Olanzapine for self-injurious, aggressive, and disruptive behaviours in intellectually disabled adults. A retrospective, open-label, naturalistic trial. Journal of Clinical Psychiatry 64, 1258-1265.

Janowsky D.S., Barnhill L.J., Shetty M. \& Davis J.M. (2005) Minimally effective doses of conventional antipsychotic medications used to treat aggression, self-injurious and destructive behaviours in mentally retarded adults. Journal of Clinical Psychopharmacology 25, 19-25.

Janowsky D.S, Kraus J.E., Barnhill J., Elamir B. \& Davis J.M. (2003a) Effects of topiramate on aggressive, selfinjurious and disruptive/destructive behaviours in the intellectually disabled. An open-label retrospective study. Journal of Clinical Psychopharmacology 23, 500-504.

Mace F.C., Blum N.J., Sierp B.J., Delaney B.A. \& Mauk J.E. (2001) Differential response of operant self-injury to pharmacologic versus behavioural treatment. Journal of Developmental \& Behavioural Pediatrics 22, 85-91.

McDonough M., Hillery J. \& Kennedy N. (2000) Olanzapine for chronic, stereotypic self-injurious behaviour. A pilot study in seven adults with intellectual disability. Journal of Intellectual Disability Research 44, 677-684.

Packman J. \& Bratton S.C. (2003) A school-based group play/activity therapy intervention with learning disabled preadolescents exhibiting behaviour problems. International Journal of Play Therapy 12, 7-29.

Pearson D.A., Santos C.W., Roache J.D., Casat C.D., Loveland K.A., Lachar D. et al. (2003) Treatment effects of methylphenidate on behavioural adjustment in children with mental retardation and ADHD. Journal of the American Academy of Child \& Adolescent Psychiatry 42, 209-216.

Plant K.M. \& Sanders M.R. (2007) Reducing problem behaviour during care-giving in families of preschoolaged children with developmental disabilities. Research in Developmental Disabilities 28, 362-385.

Read S.G. \& Rendall M. (2007) An open-label study of risperidone in the improvement of quality of life and treatment of symptoms of violent and self-injurious behaviour in adults with intellectual disability. Journal of Applied Research in Intellectual Disabilities 20, 256-264.

Roberts C., Mazzucchelli T., Studman L. \& Sanders M.R. (2006) Behavioural family intervention for children with developmental disabilities and behavioural problems. Journal of Clinical Child and Adolescent Psychology 35, 180-193.

Rose J., Loftus M., Flint B. \& Carey L. (2005) Factors associated with the efficacy of a group intervention for anger in people with intellectual disabilities. British Journal of Clinical Psychology 44, 305-317. 
Rose J., West C. \& Clifford D. (2000) Group interventions for anger in people with intellectual disabilities. Research in Developmental Disabilities 21, 171-181.

Shapira N.A., Lessig M.C., Lewis M.H., Goodman W.K. \& Driscoll D.J. (2004) Effects of topiramate in adults with Prader-Willi syndrome. American Journal on Mental Retardation 109, 301-309.

Singh N.N., Lancioni G.E., Winton A.S.W., Molina E.J., Sage M., Brown S. et al. (2004) Effects of snoezelen room, activities of daily living skills training, and vocational skills training on aggression and self-injury by adults with mental retardation and mental illness. Research in Developmental Disabilities 25, 285-293.

Snyder R., Turgay A., Aman M., Binder C., Fisman S. \& Carroll A. (2002) Effects of risperidone on conduct and disruptive behaviour disorders in children with subaverage IQ's. Journal of the American Academy of Child \& Adolescent Psychiatry 41, 1026-1036.

Taylor J.L., Novaco R.W., Gillmer B. \& Thorne I. (2002) Cognitive-behavioural treatment of anger intensity among offenders with intellectual disabilities. Journal of Applied Research in Intellectual Disabilities 15, 151165.

Turgay A., Binder C., Snyder R. \& Fisman S. (2002) Long-term safety and efficacy of risperidone for the treatment of disruptive behaviour disorders in children with subaverage IQs. Pediatrics 110, e34-e45.

Xenitidis K., Gratsa A., Bouras N., Hammond R., Ditchfield H., Holt G. et al. (2004) Psychiatric inpatient care for adults with intellectual disabilities. Generic or specialist units? Journal of Intellectual Disability Research $\mathbf{4 8}$, 11-18.

Young L. (2006) Community and cluster centre residential services for adults with intellectual disability. Longterm results from an Australian-matched sample. Journal of Intellectual Disability Research 50, 419-431.

Zarcone J.R., Hellings J.A., Crandall K., Reese R.M., Marquis J., Fleming K. et al. (2001) Effects of risperidone on aberrant behaviour of persons with developmental disabilities. A double-blind crossover study using multiple measures. American Journal on Mental Retardation 106, 525-538. 
Appendix 2: Descriptive statistics of categorical moderators

\begin{tabular}{|c|c|c|c|c|c|c|}
\hline Groups of moderators & & & & $\begin{array}{l}\text { Number } \\
\text { of studies }\end{array}$ & $\begin{array}{l}\text { Standardised } \\
\text { mean } \\
\text { difference }\end{array}$ & $\begin{array}{l}\text { Standard } \\
\text { error }\end{array}$ \\
\hline \multirow{8}{*}{$\begin{array}{l}\text { Intervention } \\
\text { characteristics }\end{array}$} & \multirow[t]{6}{*}{ Intervention type } & \multirow[t]{2}{*}{ Biological } & Yes & 18 & 0.646 & 0.068 \\
\hline & & & No & 12 & 0.707 & 0.081 \\
\hline & & \multirow[t]{2}{*}{ Psychotherapeutic } & Yes & 13 & 0.752 & 0.076 \\
\hline & & & No & 17 & 0.607 & 0.067 \\
\hline & & \multirow[t]{2}{*}{ Contextual } & Yes & 9 & 0.624 & 0.086 \\
\hline & & & No & 21 & 0.699 & 0.066 \\
\hline & \multirow{2}{*}{$\begin{array}{l}\text { Intervention } \\
\text { combination }\end{array}$} & Unimodal & & 21 & 0.674 & 0.065 \\
\hline & & Multimodal & & 9 & 0.677 & 0.089 \\
\hline \multirow[t]{20}{*}{ Methodological features } & \multirow[t]{2}{*}{ Quality assessment } & Good quality & & 22 & 0.650 & 0.060 \\
\hline & & Moderate quality & & 8 & 0.732 & 0.103 \\
\hline & \multirow[t]{6}{*}{ Study design } & \multirow[t]{2}{*}{ Experiment } & Used & 14 & 0.627 & 0.075 \\
\hline & & & Not used & 16 & 0.711 & 0.072 \\
\hline & & \multirow{2}{*}{ Quasi-experiment } & Used & 10 & 0.787 & 0.010 \\
\hline & & & Not used & 20 & 0.631 & 0.058 \\
\hline & & \multirow[t]{2}{*}{ Natural experiment } & Used & 6 & 0.637 & 0.102 \\
\hline & & & Not used & 24 & 0.684 & 0.061 \\
\hline & \multirow[t]{10}{*}{ Data collection } & \multirow[t]{2}{*}{ Test } & Used & 9 & 0.726 & 0.090 \\
\hline & & & Not used & 21 & 0.643 & 0.064 \\
\hline & & \multirow[t]{2}{*}{ Questionnaire } & Used & 22 & 0.647 & 0.060 \\
\hline & & & Not used & 8 & 0.746 & 0.105 \\
\hline & & \multirow[t]{2}{*}{ Observation } & Used & 9 & 0.723 & 0.103 \\
\hline & & & Not used & 21 & 0.653 & 0.061 \\
\hline & & \multirow[t]{2}{*}{ Interview } & Used & 11 & 0.716 & 0.076 \\
\hline & & & Not used & 19 & 0.632 & 0.070 \\
\hline & & \multirow[t]{2}{*}{ Other } & Used & 8 & 0.530 & 0.088 \\
\hline & & & Not used & 22 & 0.735 & 0.060 \\
\hline & \multirow{2}{*}{ Reliability } & Reported & & 16 & 0.657 & 0.074 \\
\hline & & Not reported & & 14 & 0.686 & 0.075 \\
\hline Study characteristics & Research period & Less than 1 year & & 13 & 0.624 & 0.085 \\
\hline & & More than 1 year & & 10 & 0.699 & 0.096 \\
\hline & & No information & & 7 & 0.705 & 0.096 \\
\hline & Continent & America & & 14 & 0.676 & 0.077 \\
\hline & & Europe & & 11 & 0.745 & 0.093 \\
\hline & & Other & & 5 & 0.563 & 0.107 \\
\hline Participant features & Gender & $\begin{array}{l}\text { More female } \\
\text { participants }\end{array}$ & & 6 & 0.680 & 0.105 \\
\hline & & More male participant & & 21 & 0.693 & 0.064 \\
\hline & & Equal / no information & & 3 & 0.472 & 0.181 \\
\hline & Age & Mean $<18$ years & & 11 & 0.559 & 0.074 \\
\hline & & Mean $>18$ years & & 16 & 0.770 & 0.077 \\
\hline & & No information & & 3 & 0.736 & 0.139 \\
\hline & Degree of ID & Mild ID & Yes & 16 & 0.637 & 0.068 \\
\hline & & & No & 8 & 0.646 & 0.113 \\
\hline & & & No information & 6 & 0.795 & 0.115 \\
\hline & & Moderate ID & Yes & 14 & 0.592 & 0.065 \\
\hline & & & No & 10 & 0.766 & 0.108 \\
\hline & & & No information & 6 & 0.792 & 0.110 \\
\hline & & Severe ID & Yes & 15 & 0.653 & 0.073 \\
\hline & & & No & 9 & 0.616 & 0.097 \\
\hline & & & No information & 6 & 0.794 & 0.115 \\
\hline & & Profound ID & Yes & 8 & 0.774 & 0.126 \\
\hline & & & No & 16 & 0.605 & 0.063 \\
\hline & & & No information & 6 & 0.792 & 0.111 \\
\hline
\end{tabular}

